\title{
Genetic polymorphisms of the FATP1 gene and their associations with meat quality traits in Chinese Qinchuan cattle
}

\author{
Z.D. Zhao', A.N. Li' ${ }^{1}$, S.J. Wei ${ }^{1}$, M.M. Wang ${ }^{1}$, S.J. Li ${ }^{1}$ and L.S. Zan ${ }^{1,2}$ \\ ${ }^{1}$ College of Animal Science and Technology, Northwest A\&F University, Yangling, \\ Shaanxi, China \\ ${ }^{2}$ National Beef Cattle Improvement Center of Northwest A\&F University, Yangling, \\ Shaanxi, China \\ Corresponding author: L.S. Zan \\ E-mail: zanlinsen@163.com
}

Genet. Mol. Res. 14 (4): 17439-17446 (2015)

Received September 18, 2015

Accepted November 11, 2015

Published December 21, 2015

DOI http://dx.doi.org/10.4238/2015.December.21.14

\begin{abstract}
Fatty acid transport protein 1 (FATP1), an integral membrane protein that facilitates long-chain fatty acid influx, is involved in the genetic network for oleic acid synthesis. The aim of this study was to examine the association of FATP1 polymorphisms with live animal meat quality traits in Chinese Qinchuan cattle. Quantitative real-time PCR analysis demonstrated that FATP1 has a broad tissue distribution in Qinchuan cattle and is highly expressed in longissimus dorsi muscle and back fat. Using direct DNA sequencing of the FATP1 gene in 458 Qinchuan cattle, four single nucleotide polymorphisms (SNPs; g.28265 G>C, g.28381 G>A, g.28470 T>C, and g.28672 G>A) were identified for genotyping within a 671-bp region, including exon 3 , intron 3 , exon 4 , intron 4 , and part of exon 5 of the FATP1 gene. Positive effects of genotypes CC (g.28470 T>C locus) and AA (g.28672 G>A locus) on meat quality traits were obtained by association analysis. These results indicate the associations of g.28470 $\mathrm{T}>\mathrm{C}$ and g.28672 G>A with meat quality traits in Qinchuan cattle. Thus,
\end{abstract}


the FATP1 gene may be used in marker-assisted selection of beef cattle in breeding programs.

Key words: FATP1 gene; Molecular markers; Meat quality traits; Tissue expression; Qinchuan cattle

\section{INTRODUCTION}

Intramuscular fat (IMF), or marbling, in longissimus dorsi muscle (LM) tissue of cattle is an important meat quality indicator that influences beef juiciness, tenderness, and taste (Hovenier et al., 1993; Hausman et al., 2009). Intramuscular fat deposition and fatty acid profiles of beef are mainly determined by lipid metabolism, which dictates the balance between fat deposition and fat removal in LM. IMF deposition is influenced by several factors, such as breed, genotype, gender, and nutrition (Maltin et al., 2003). In addition, castration increases IMF deposition in Korean cattle (Bong et al., 2012), resulting in improved beef quality. Large variation in IMF content remains in Korean cattle steers, which suggests that beef quality can be further improved.

Fatty acid transport protein 1 (FATP1) is an integral membrane protein that facilitates longchain fatty acids (LCFAs) influx by coupling the diffusion with coenzyme A (CoA)-esterification on the inner membrane (Schaffer and Lodish, 1994; Hall et al., 2003). One functional motif of FATP1 is essential for the transport function and mutations within this motif result in diminished LCFA transport activity (Stuhlsatz-Krouper et al., 1998; Stuhlsatz-Krouper et al., 1999). Further, overexpression of FATP1 in skeletal muscle increases the partitioning of oleate or palmitate into triacylglyceride (TAG) and away from $\beta$-oxidation (Garcia-Martinez et al., 2005). Intronic polymorphism in the FATP1 gene was found to be associated with increased fasting plasma triglyceride levels in a French population (Meirhaeghe et al., 2000). Association analysis revealed that single nucleotide polymorphisms (SNPs) in the chicken FATP1 gene have an effect on chicken carcass traits (Wang et al., 2010). The gene expression abundance of FATP1 has also been observed to exhibit significant positive correlations $(P<0.05)$ with IMF content in the LM (Jeong et al., 2012). In addition, this gene consists of 13 exons spanning approximately $40 \mathrm{~kb}$ of genomic DNA (Ordovas et al., 2006) and the gene maps in BTA (Bos taurus ) 7 (Ordovas et al., 2005), where several quantitative trait loci (QTL) for fat related traits have been found (Casas et al., 2003). Thus, the FATP1 gene is important in the context of beef production.

Based on its important functions concerning LCFAs uptake and TAG metabolism in adipocytes and skeletal muscle, FATP1 could be an attractive candidate gene for use in genetic selection programs. The aim of this study was to examine SNPs in the bovine FATP1 gene, and carry out association analysis to better understand FATP1 functions in variation of beef quality in Qinchuan cattle.

\section{MATERIAL AND METHODS}

\section{RNA isolation and reverse transcription}

Twelve tissues, including heart, LM, back fat, large intestine, kidney, testicular fat, rumen, small intestine, liver, cecum, spleen, and lung tissue, were obtained from three Chinese Qinchuan bulls (24 months) immediately after slaughter. Total RNA was extracted from the tissues for reverse transcription using a simple Total RNA kit (Tiangen, Beijing, China). Reverse transcription reactions 
were performed using PrimeScript ${ }^{\mathrm{TM}}$ RT reagent kit with gDNA Eraser (TaKaRa, Dalian, China) following the manufacturer protocol.

\section{SYBR Green qPCR for detecting FATP1 gene expression in tissues}

qPCR was performed using the SYBR Green PCR Master Mix kit (TaKaRa) and the 7500 System SDS Software V1.4.0 (Applied Biosystems, USA). PCR was carried out in a final $20 \mu \mathrm{L}$ volume, consisting of $10 \mu \mathrm{L}$ SYBR Green Premix Ex TaqTM, $0.4 \mu \mathrm{M}$ each forward and reverse primer, and $2-\mu \mathrm{L}$ RT reaction solution. Each sample was detected in triplicate using the following conditions: $95^{\circ} \mathrm{C}$ for $30 \mathrm{~s}$ followed by 40 cycles of $95^{\circ} \mathrm{C}$ for $5 \mathrm{~s}$ and $60^{\circ} \mathrm{C}$ for $30 \mathrm{~s}$. Primers used in the qPCR analysis are listed in Table 1. Levels of mRNA expression were normalized with bovine GAPDH and ACTB (endogenous genes). Relative expression levels of objective mRNA were calculated using the $2_{T}^{-\Delta \Delta C}$ method (Livak and Schmittgen, 2001).

\begin{tabular}{|c|c|c|c|c|}
\hline Primer & Sequence $\left(5^{\prime}-3^{\prime}\right)$ & Annealing temperature $\left({ }^{\circ} \mathrm{C}\right)$ & Product length (bp) & Reference sequence \\
\hline \multirow[t]{2}{*}{ FATP1-qPCR } & F: AAGAGCCTGGTCAAGTTCTG & 60 & 239 & NM_001033625 \\
\hline & R: TAGGAGTAGTGCCCAAATGC & & & \\
\hline \multirow[t]{2}{*}{ GAPDH-qPCR } & F: CGACTTCAACAGCGACACTCAC & 60 & 118 & NM_001034034.2 \\
\hline & R: CCCTGTTGCTGTAGCCAAATTC & & & \\
\hline \multirow[t]{2}{*}{ ACTB-qPCR } & F: CATCGGCAATGAGCGGTTCC & 60 & 147 & NM_173979 \\
\hline & R: ACCGTGTTGGCGTAGAGGTC & & & \\
\hline \multirow[t]{2}{*}{ FATP1-F } & F: ACGCTGTGGCCAACTTGTTC & 58 & 671 & AC_000164.1 \\
\hline & R: ACCTGCTGTGCACGATGATG & & & \\
\hline
\end{tabular}

\section{Sampling and DNA isolation for genetic polymorphism}

In order to explore the genetic variation in bovine FATP1, a total of 458 (18 to 24 months old) adult animals from the experiment farm of the national beef cattle improvement center were selected and fed under the same management conditions. Blood samples for DNA isolation were collected from the jugular vein of each animal. Genomic DNA was extracted using the standard phenol-chloroform protocol (Mullenbach et al., 1989), and then diluted to $50 \mathrm{ng} / \mu \mathrm{L}$ for SNP identification and genotyping.

Three meat quality traits, including backfat thickness (BFT), loin muscle area (LMA), and IMF, were measured for association analysis by ultrasound of the live animal as described previously (Rincon et al., 2009).

\section{SNP identification}

To identify SNPs in the FATP1 gene, primers (Table 1) were designed to amplify a 671-bp product from exon 3 to part of exon 5. PCR was performed in a $25-\mu \mathrm{L}$ reaction volume, including $50 \mathrm{ng}$ genomic DNA, $10 \mathrm{pM}$ each primer, $0.20 \mathrm{mM} \mathrm{dNTP}, 2.5 \mathrm{mM} \mathrm{MgCl}$, and $0.5 \mathrm{U}$ of Taq DNA polymerase (TaKaRa). PCR conditions were as follows: $95^{\circ} \mathrm{C}$ for $5 \mathrm{~min}$, followed by 35 cycles of $94^{\circ} \mathrm{C}$ for $30 \mathrm{~s}, 58^{\circ} \mathrm{C}$ annealing for $30 \mathrm{~s}, 72^{\circ} \mathrm{C}$ for $45 \mathrm{~s}$, and a final extension at $72^{\circ} \mathrm{C}$ for $8 \mathrm{~min}$.

The DNA samples of 10 individuals were selected randomly and pooled for PCR. PCR products were sequenced in both directions (Jinsirui, Nanjing, China) and SNPs were identified by visually inspecting sequence patterns. 


\section{Genotyping}

All of the PCR products from the 458 Qinchuan cattle sampled were sequenced in both directions (Jinsirui), and the sequences were analyzed using the DNASTAR 6.0 package (DNASTAR, Inc., USA) for genotyping.

\section{Statistical analysis}

Genotype frequencies, allele frequencies, $\chi^{2}$ values of Hardy-Weinberg equilibrium (HWE), homozygosity $\left(H_{\mathrm{O}}\right)$, heterozygosity $\left(H_{\mathrm{E}}\right)$, and polymorphism information content (PIC) were statistically analyzed according to previous reports (Nei and Roychoudhury, 1974). The association between SNP marker genotypes of the FATP1 gene and records of ultrasound measurement traits (BFT, LMA, and IMF) were analyzed using SPSS 16.0 according to the following statistical linear model:

$$
Y_{i j k l m}=u+G_{i}+A_{j}+A_{k}+S_{l}+S_{m}+E_{i j k l m}
$$

where, $Y_{i j k l m}$ is the trait measured on each individual animal, $\mu$ is the overall population mean for the trait, $G_{i}$ is the fixed effect associated with the genotype, $A_{i}$ is the fixed effect due to age, $A_{k}$ is the fixed effect due to the age of the dam, $S_{1}$ is the fixed effect due to the season of sampling (spring $v s$ fall), $S_{m}$ is the fixed effect due to the sire, and $E_{i \mathrm{jklm}}$ is the standard error.

\section{RESULTS AND DISCUSSION}

\section{Expression of FATP1 in Qinchuan cattle tissues and organs}

To detect the tissue distribution of bovine FATP1 mRNA, qPCR was performed with cDNA from tissues and organs of three 2-year-old Qinchuan bulls.As shown in Figure 1, qPCR analysis revealed that FATP1 has a broad tissue distribution in Qinchuan cattle tissues and organs. The basal expression of FATP1 was relatively high in heart, LM, and back fat, but low in the cecum, spleen, and lung tissue. FATP1 has also been shown to be highly expressed in both human and mouse tissues exhibiting rapid fatty acid metabolism, such as skeletal muscle, adipose tissue, heart, and brain (Schaffer and Lodish, 1994; Hui et al., 1998; Martin et al., 2000). The intramuscular fat deposition and fatty acid profiles of beef are mainly determined by lipid metabolism, which indicates that FATP1 may play an important role in IMF deposition and the fatty acid profiles of beef.

\section{Polymorphisms of FATP1 via sequencing}

In the present study, the 671-bp PCR product, including exon 3, intron 3, exon 4, intron 4, and part of exon 5, of the FATP1 gene in Qinchuan cattle was amplified. Four SNPs (g.28265 G>C, g.28381 G>A, g.28470 T>C, and g.28672 G>A) were identified by direct DNA sequencing (Figure 2). The four SNPs were named according to their position in the sequence of the FATP1 gene. The g.28381 G>A was in intron 3, and g.28265 G>C, g.28470 T>C, and g.28672 G>A were silent mutations found in exons 3,4, and 5, respectively. Since IMF deposition and the fatty acid profiles of beef affect meat quality (Widmann et al., 2011), and the gene expression abundance of 
FATP1 has been shown to exhibit significant positive correlations $(P<0.05)$ with IMF content in LM (Jeong et al., 2012), it was hypothesized that this mutation may influence FATP1 protein synthesis. However, this needs to be validated in future studies.

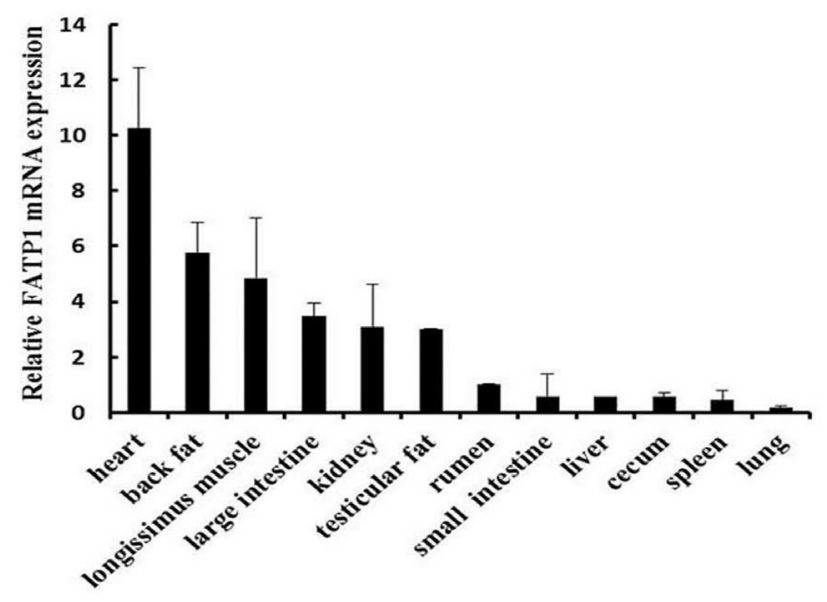

Figure 1. Tissue expression analysis of FATP1 mRNA in Qinchuan cattle.
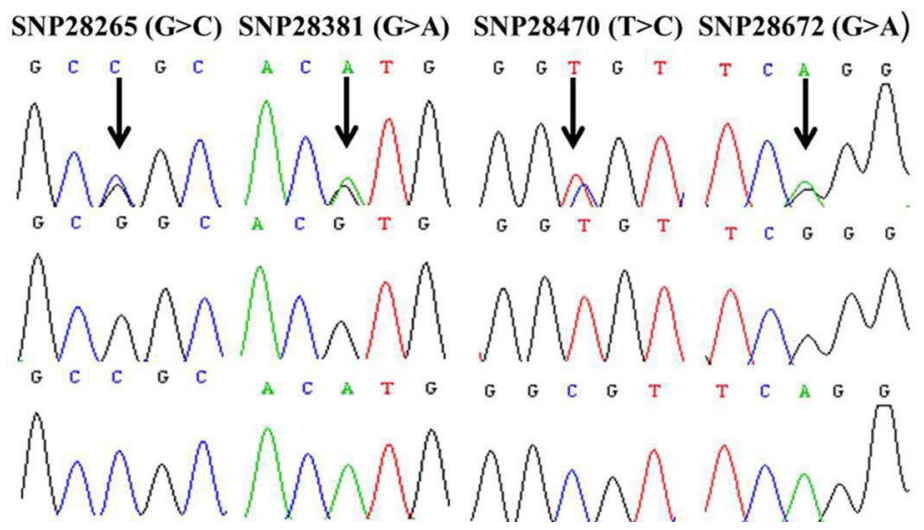

Figure 2. Sequencing identification of the four single nucleotide polymorphisms (SNPs) within the bovine FATP1 gene, based on GenBank accession No. AC_000164.1.

\section{Genetic diversity of the FATP1 gene in the Qinchuan cattle population}

Genotype and allele frequencies were calculated and genetic indices of the Qinchuan cattle population are described in Table 2. The $\chi^{2}$ test indicated that HWE was observed at the g.28265 G>C and g.28381 G>A loci $\left(\chi^{2}<\chi_{0.05}^{2}\right)$, while the genotypic frequencies of g.28470 T>C and g.28672 G>A deviated from HWE in the studied population $\left(\chi^{2}>\chi_{0.01}^{2}\right)$. These results indicate that dominant alleles may have been preserved in the Qinchuan cattle population, while inferior alleles may have been weakened following long-term artificial selection, which ultimately resulted in the variation in allele and genotype frequencies that deviated from HWE. $H_{\mathrm{E}}$ (gene heterozygosity) ranged from 0.31 to 0.49 , and $N_{E}$ (effective allele number) ranged from 1.45 to 1.98. The maximum 
and minimum PIC values were 0.37 and 0.26 , respectively. According to the classification of PIC (low polymorphism if PIC value $<0.25$, median polymorphism if $0.25<\mathrm{PIC}<0.5$, and high polymorphism if PIC value $>0.5$ ), the studied population possessed a moderate genetic diversity at the four SNP loci. These data reflect low genetic diversity within the Qinchuan cattle FATP1 gene in the analyzed population. Genetic diversity is essential for preservation of the adaptive potential of species and improvements in production potential of highly selected breeds.

Table 2. Genotype and allele frequencies (\%), value of $\chi^{2}$ test, and diversity parameters of single nucleotide polymorphisms (SNPs) in the FATP1 gene in Qinchuan cattle.

\begin{tabular}{|c|c|c|c|c|c|c|c|c|c|c|}
\hline \multirow{2}{*}{$\frac{\text { SNP }}{\text { g.28265 G>C }}$} & \multirow{2}{*}{$\frac{\text { No. of samples }}{458}$} & \multicolumn{3}{|c|}{ Genotype frequency } & \multicolumn{2}{|c|}{ Allele frequency } & \multirow{3}{*}{$\begin{array}{c}H_{\mathrm{E}} \\
0.4609\end{array}$} & \multirow{3}{*}{$\frac{N_{\mathrm{E}}}{1.8551}$} & \multirow{3}{*}{$\begin{array}{c}\text { PIC } \\
0.3547\end{array}$} & \multirow{3}{*}{$\begin{array}{r}\chi^{2} \text { (HWE) } \\
4.5809\end{array}$} \\
\hline & & GG & GC & $\mathrm{CC}$ & G & C & & & & \\
\hline & & 0.4323 & 0.4148 & 0.1528 & 0.6397 & 0.3603 & & & & \\
\hline \multirow[t]{2}{*}{ g.28381 G>A } & 458 & GG & GA & AA & G & A & & & & \\
\hline & & 0.6650 & 0.3013 & 0.0437 & 0.8057 & 0.1943 & 0.3131 & 1.4559 & 0.2641 & 0.6519 \\
\hline \multirow[t]{2}{*}{ g.28470 T>C } & 458 & TT & $\mathrm{TC}$ & $\mathrm{CC}$ & $\mathrm{T}$ & C & & & & \\
\hline & & 0.2576 & 0.3843 & 0.3581 & 0.4498 & 0.5502 & 0.4950 & 1.9800 & 0.3725 & 22.9005 \\
\hline \multirow[t]{2}{*}{ g.28672 G>A } & 458 & GG & GA & $\mathrm{AA}$ & G & A & & & & \\
\hline & & 0.4367 & 0.3231 & 0.2402 & 0.5983 & 0.4017 & 0.4807 & 1.9256 & 0.3652 & 49.1993 \\
\hline
\end{tabular}

HWE, Hardy-Weinberg equilibrium; $\chi_{0.05}^{2}=5.991, \chi_{0.01}^{2}=9.21$; PIC, polymorphism information content.

\section{Association of polymorphism with meat quality traits}

FATP1 is a plasma membrane protein expressed in adipose tissue, heart, and skeletal muscle of bovine (Ordovas et al., 2006). Previous studies have demonstrated that depletion of FATP1 leads to redistribution of postprandial fatty acid uptake and triglyceride deposition in adipose tissue and muscle of mice (Wu et al., 2006; Gimeno, 2007). Zhang et al. (2012) confirmed that FATP1 was involved in the genetic network for oleic acid, providing useful targets for improving meat quality traits and healthy beef products in cattle. Therefore, the FATP1 gene is considered one of the important candidate genes that are possible markers for meat quality traits. In this study, we found three synonymous SNPs and one intronic variant in the bovine FATP1 gene. However, a series of studies have shown that synonymous SNPs can influence gene expression via changes in secondary structures of mRNA and, thereby, the length of pause cycles during translation, the overall rate of translation, or protein folding (Kimchi-Sarfaty et al., 2007; Bartoszewski et al., 2010). Greenwood and Kelsoe (2003) reported that intronic variants can affect the transcription efficiency of numerous genes.

Hence, the relationship between the variations we found in the FATP1 gene and meat quality traits were analyzed in Qinchuan cattle (Table 3). Specifically, at the g.28470 T>C locus, individuals with genotype CC had greater BFT than those with the TT genotype $(P<0.05)$; and individuals with genotypes CC and TC had higher IMF than those with the TT genotype $(P<0.05)$, suggesting that the $C$ in the g.28470 T>C locus may be associated with improvements in meat quality traits. At the g.28672 G>A locus, individuals with genotype AA had higher IMF than those with the GA and GG genotypes ( $P<0.05$ ), suggesting that the $A$ in the g.28672 G>A locus may be associated with improved meat quality traits. In addition, individuals with genotype AA showed greater LMA than those with the GG genotype $(P<0.05)$. Regrettably, no associations with meat quality traits were identified at the g.28265 G>C or g.28381 G>A loci.

In summary, we showed that the FATP1 gene is highly expressed in LM and back fat in Qinchuan cattle. Our findings suggest an association between SNPs g.28470 T>C and g.28672 
G>A in FATP1 and meat quality traits in Qinchuan cattle, which indicates that FATP1 could be used in marker-assisted selection of beef cattle. Therefore, considering the superiority of genotypes CC (g.28470 T>C locus) and AA (g.28672 G>A locus), it is worthwhile and necessary to preserve and utilize these during the cattle breeding practice.

\begin{tabular}{|c|c|c|c|c|c|c|}
\hline \multirow[t]{2}{*}{ Meat quality trait } & \multirow[t]{2}{*}{ SNP } & \multirow[t]{2}{*}{ Variant location } & \multicolumn{3}{|c|}{ Genotypes (mean \pm SE) } & \multirow[t]{2}{*}{$P$} \\
\hline & & & $x x$ & XO & $\mathrm{OO}$ & \\
\hline \multirow[t]{4}{*}{ Backfat thickness (cm) } & g.28265 G>C & Exon 3 & $0.898 \pm 0.021$ & $0.937 \pm 0.021$ & $0.980 \pm 0.035$ & 0.185 \\
\hline & g.28381 G>A & Intron 3 & $0.923 \pm 0.016$ & $0.932 \pm 0.023$ & $0.950 \pm 0.061$ & 0.283 \\
\hline & g.28470 T>C & Exon 4 & $0.846 \pm 0.027^{\mathrm{b}}$ & $0.917 \pm 0.22$ & $0.944 \pm 0.023^{a}$ & 0.024 \\
\hline & g. $28672 \mathrm{G}>\mathrm{A}$ & Exon 5 & $0.905 \pm 0.021$ & $0.940 \pm 0.024$ & $0.892 \pm 0.028$ & 0.197 \\
\hline \multirow[t]{4}{*}{ Loin muscle area $\left(\mathrm{cm}^{2}\right)$} & g.28265 G>C & Exon 3 & $47.555 \pm 0.902$ & $49.092 \pm 0.920$ & $48.612 \pm 1.516$ & 0.050 \\
\hline & g.28381 G>A & Intron 3 & $47.668 \pm 0.734$ & $47.819 \pm 1.082$ & $48.488 \pm 2.842$ & 0.887 \\
\hline & g.28470 T>C & Exon 4 & $47.511 \pm 1.173$ & $47.762 \pm 0.960$ & $48.389 \pm 0.995$ & 0.569 \\
\hline & g.28672 G>A & Exon 5 & $46.344 \pm 0.896^{b}$ & $49.009 \pm 1.041$ & $49.327 \pm 1.208^{\mathrm{a}}$ & 0.048 \\
\hline \multirow[t]{4}{*}{ Intramuscular fat (\%) } & g.28265 G>C & Exon 3 & $7.784 \pm 0.048$ & $7.850 \pm 0.049$ & $7.949 \pm 0.081$ & 0.082 \\
\hline & g.28381 G>A & Intron 3 & $7.806 \pm 0.039$ & $7.890 \pm 0.058$ & $7.927 \pm 0.152$ & 0.108 \\
\hline & g.28470 T>C & Exon 4 & $7.676 \pm 0.062^{\mathrm{b}}$ & $7.868 \pm 0.051^{\mathrm{a}}$ & $7.919 \pm 0.053^{a}$ & 0.032 \\
\hline & g.28672 G>A & Exon 5 & $7.748 \pm 0.048^{b}$ & $7.751 \pm 0.056^{b}$ & $7.985 \pm 0.064^{a}$ & 0.041 \\
\hline
\end{tabular}

$\mathrm{XX}=$ the common allele; $\mathrm{XO}=$ the heterozygotes; $\mathrm{OO}=$ the homozygotes for the mutated allele. ${ }^{\mathrm{a}, \mathrm{b}}$ Means with different superscripts were significantly different $(P<0.05)$.

\section{Conflicts of interest}

The authors declare no conflict of interest.

\section{ACKNOWLEDGMENTS}

Research supported by the National "863" Program of China (\#2013AA102505 and \#2011AA100307-02), the National Natural Science Foundation (\#31272411), the National Beef and Yak Industrial Technology System (\#CARS-38), the National Science-Technology Support Plan Projects (\#2012BAD28B04-03), and the Technical Innovation Engineering Project of Shaanxi Province (\#2014 KTZB02-02-01).

\section{REFERENCES}

Bartoszewski RA, Jablonsky M, Bartoszewska S, Stevenson L, et al. (2010). A synonymous single nucleotide polymorphism in DeltaF508 CFTR alters the secondary structure of the mRNA and the expression of the mutant protein. J. Biol. Chem. 285: 28741-28748.

Bong JJ, Jeong JY, Rajasekar P, Cho YM, et al. (2012). Differential expression of genes associated with lipid metabolism in longissimus dorsi of Korean bulls and steers. Meat Sci. 91: 284-293.

Casas E, Shackelford SD, Keele JW, Koohmaraie M, et al. (2003). Detection of quantitative trait loci for growth and carcass composition in cattle. J. Anim. Sci. 81: 2976-2983.

Garcia-Martinez C, Marotta M, Moore-Carrasco R, Guitart M, et al. (2005). Impact on fatty acid metabolism and differential localization of FATP1 and FAT/CD36 proteins delivered in cultured human muscle cells. Am. J. Physiol. Cell Physiol. 288: C1264-C1272.

Gimeno RE (2007). Fatty acid transport proteins. Curr. Opin. Lipidol. 18: 271-276.

Greenwood TA and Kelsoe JR (2003). Promoter and intronic variants affect the transcriptional regulation of the human dopamine transporter gene. Genomics 82: 511-520. 
Hall AM, Smith AJ and Bernlohr DA (2003). Characterization of the Acyl-CoA synthetase activity of purified murine fatty acid transport protein 1. J. Biol. Chem. 278: 43008-43013.

Hausman GJ, Dodson MV, Ajuwon K, Azain M, et al. (2009). Board-invited review: the biology and regulation of preadipocytes and adipocytes in meat animals. J. Anim. Sci. 87: 1218-1246.

Hovenier R, Kanis E and Verhoeven JA (1993). Repeatability of taste panel tenderness scores and their relationships to objective pig meat quality traits. J. Anim. Sci. 71: 2018-2025.

Hui TY, Frohnert BI, Smith AJ, Schaffer JE, et al. (1998). Characterization of the murine fatty acid transportprotein gene and its insulin response sequence. J. Biol. Chem. 273: 27420-27429.

Jeong J, Kwon EG, Im SK, Seo KS, et al. (2012). Expression of fat deposition and fat removal genes is associated with intramuscular fat content in longissimus dorsi muscle of Korean cattle steers. J. Anim. Sci. 90: 2044-2053.

Kimchi-Sarfaty C, Oh JM, Kim IW, Sauna ZE, et al. (2007). A "silent" polymorphism in the MDR1 gene changes substrate specificity. Science 315: 525-528.

Livak KJ and Schmittgen TD (2001). Analysis of relative gene expression data using real-time quantitative PCR and the 2(-Delta Delta $\mathrm{C}(\mathrm{T})$ ) method. Methods 25: 402-408.

Martin G, Nemoto M, Gelman L, Geffroy S, et al. (2000). The human fatty acid transport protein-1 (SLC27A1; FATP-1) cDNA and gene: organization, chromosomal localization, and expression. Genomics Maltin C, Balcerzak D, Tilley R and Delday M (2003). Determinants of meat quality: tenderness. Proc. Nutr. Soc. 62: 337-347.

Meirhaeghe A, Martin G, Nemoto M, Deeb S, et al. (2000). Intronic polymorphism in the fatty acid transport protein 1 gene is associated with increased plasma triglyceride levels in a French population. Arterioscler. Thromb. Vasc. Biol. 20: 1330-1334.

Mullenbach R, Lagoda PJ and Welter C (1989). An efficient salt-chloroform extraction of DNA from blood and tissues. Trends Genet. 5: 391.

Nei M and Roychoudhury AK (1974). Sampling variances of heterozygosity and genetic distance. Genetics 76: 379-390.

Ordovas L, Roy R, Zaragoza P, Hayes H, et al. (2005). Assignment of the solute carrier family 27 member 1 (SLC27A1) gene to bovine chromosome 7. Anim. Genet. 36: 352-353.

Ordovas L, Roy R, Zaragoza P and Rodellar C (2006). Structural and functional characterization of the bovine solute carrier family 27 member 1 (SLC27A1) gene. Cytogenet. Genome Res. 115: 115-122.

Rincon G, Farber EA, Farber CR, Nkrumah JD, et al. (2009). Polymorphisms in the STAT6 gene and their association with carcass traits in feedlot cattle. Anim. Genet. 40: 878-882.

Schaffer JE and Lodish HF (1994). Expression cloning and characterization of a novel adipocyte long chain fatty acid transport protein. Cell 79: 427-436.

Stuhlsatz-Krouper SM, Bennett NE and Schaffer JE (1998). Substitution of alanine for serine 250 in the murine fatty acid transport protein inhibits long chain fatty acid transport. J. Biol. Chem. 273: 28642-28650.

Stuhlsatz-Krouper SM, Bennett NE and Schaffer JE (1999). Molecular aspects of fatty acid transport: mutations in the IYTSGTTGXPK motif impair fatty acid transport protein function. Prostaglandins Leukot. Essent. Fatty Acids 60: 285-289.

Wang Y, Zhu Q, Zhao XL, Yao YG, et al. (2010). Association of FATP1 gene polymorphisms with chicken carcass traits in Chinese meat-type quality chicken populations. Mol. Biol. Rep. 37: 3683-3690.

Widmann P, Nuernberg K, Kuehn C and Weikard R (2011). Association of an ACSL1 gene variant with polyunsaturated fatty acids in bovine skeletal muscle. BMC Genet. 12: 96.

Wu Q, Ortegon AM, Tsang B, Doege H, et al. (2006). FATP1 is an insulin-sensitive fatty acid transporter involved in dietinduced obesity. Mol. Cell. Biol. 26: 3455-3467.

Zhang L, Michal JJ, O'Fallon JV, Pan Z, et al. (2012). Quantitative genomics of 30 complex phenotypes in Wagyu x Angus $F(1)$ progeny. Int. J. Biol. Sci. 8: 838-58. 